\title{
Development of Complex Solar LED Lighting Security System Applying Signal Processing-Based Sound Recognition Technology
}

\author{
Wonchul Choi ${ }^{1}$ and Choongchae Woo ${ }^{2}$ \\ ${ }^{1,2}$ Department of Electronic Engineering, Hanseo Univ, Seosan, Korea \\ ${ }^{1}$ comling2497@gmail.com, ${ }^{2}$ Woo9@hanseo.ac.kr
}

\begin{abstract}
Solar power plants are expensive when expensive facilities are disclosed to the outside, and the generation of panels is stolen and the solar cells are damaged. Therefore, a security system is being built by deploying regular security personnel at power stations and operating infrared sensor alarm system and security camera independently. In this paper is a solar LED light / streetlight application product that combines hybrid type solar battery charge controller with signal processing and sensor network technology. Based on the convergence of IT technology, smart control and management system for solar LED lighting system is widely applied. By combining moving object recognition technology and mismatch control technology between solar modules, we have developed a mobile-recognized solar LED lighting system. We have also developed a large-scale facility and a large-scale facility through an intruder detection system, network video and intruder monitoring, Equipment security system.
\end{abstract}

Keywords: Solar, LED, Street light, signal processing, sound recognition

\section{Introduction}

The security system for the costly large-scale facilities such as solar power plants can be established by utilizing smart control and management systems for the solar LED lighting system based on the convergence of IT technologies. Discontinuation of solar power generation due to stolen panels and damaged solar cells causes significant loss. In fact, the solar power plant built in Veliko Tarnovo, Bulgaria places security personnel available for 24 hours and separately operates the infrared sensor alarm system and the security camera to counteract the gypsies aiming at stealing highly expensive facilities. Damages and losses of large-scale facilities and equipment might be reduced via atomization and monitoring of such security systems to be integrated as one system[2-4].

The protective wall is created between solar LED lights by using the IT sensor. If the intruder enters into the sensor wall, the light becomes turn on and relevant information is sent to the control center, so the manager could understand the situation in real time from the location of intruder indicated in the monitoring system. At the same time, information on the intruder is taken by the IP Camera as soon as the LED is lighted and sent to the PC at the control tower to be saved. In addition, not only the control center monitors camera video and intruder information via integrated management and remote control system but also the manager sets the continual lighting night time of overall LET lights and remotely and manually controls the LED lights, resulting in minimization of personnel necessary for maintaining security. In emergency when the manager is unavailable the control center, the security system can be maintained for 24 hours by surveillance/control applications interlocked with the mobile communication devices for integrated management and remote control[5-7].

Received (January 3, 2018), Review Result (March 9, 2018), Accepted (March 12, 2018) 


\section{Core Technology Development}

This system consists of core technologies such as the solar LED lighting charge controller, the plumbic acid/lithium-ion battery pack device, wireless sensor network, and integrated management and remote control system.

\subsection{Solar LED Lighting Charge Controller for MPPT Plumbic Acid/Lithium-Ion}

The solar LED lighting charge controller for MPPT plumbic acid/lithium-ion consists of MPPT function to optimize the solar irradiance on the solar panel and output changing over surroundings and the plumbic acid battery/lithium ion battery charge controller and the hybrid system turning on LED light by conventionally convertible upon deterioration of charging environment such as winter or rainy season.

The solar lighting charge controller for plumbic acid battery only currently available in the market is an already universal technology that has a limit to be used for lighting or security light due to the low electric conversion efficacy and the limited storage battery level. Therefore, the solar LED lighting controller including the complex sensing module for monitoring status of charge controller operation and battery charge/discharge and the wireless sensor network module for data communication was developed, which provides MPPT control/charge function for Li-ion battery, conventional convertible function upon deterioration of environment and stable system operation and maintenance. It is expected to replace the current solar lighting system using previous lead battery with the stable power supply and environment-friendly charge/discharge system applying Li-ion battery [1, 8-9].

The technology of MPPT charge controller is mainly characterized as the solar lighting security system consisting of two $230 \mathrm{w}$ modules with three operating voltage range of 12 $\mathrm{V}, 24 \mathrm{~V}$ and $48 \mathrm{~V}$ per composition of Li-ion battery pack to be used as a storage system and $500 \mathrm{w}$ of the charging capacity. In addition, it is operated to detect and send data and information such as solar lighting module, battery voltage, current and temperature indicating light as well as normal operation of charge controller and battery pack to the integrated monitoring system via wireless communication. Overall system diagram is provided in Figure 1.

\subsection{BMS (Battery Management System) for Li-ion battery pack Related Work}

The Li-ion battery replaceable with previous plumbic acid battery, environmentfriendly and useful for maintenance is configured as an energy storage device for solar LED lighting and security system. The lamination/packing of Li-ion battery is operated by three forms of voltage for the MPPT-applied charge controller system, $12 \mathrm{~V}, 24 \mathrm{~V}$ and 48 $\mathrm{V}$. The BMS incorporates the sensor part to detect voltage, current and temperature with the battery pack for easy repair and maintenance, include switching function to control and balance low voltage cells with the voltage level of other cells in the battery pack by determining sensing data including over-charge/over-discharge of battery and performs wireless communication with the charge controller for stable operation of Li-ion battery. 


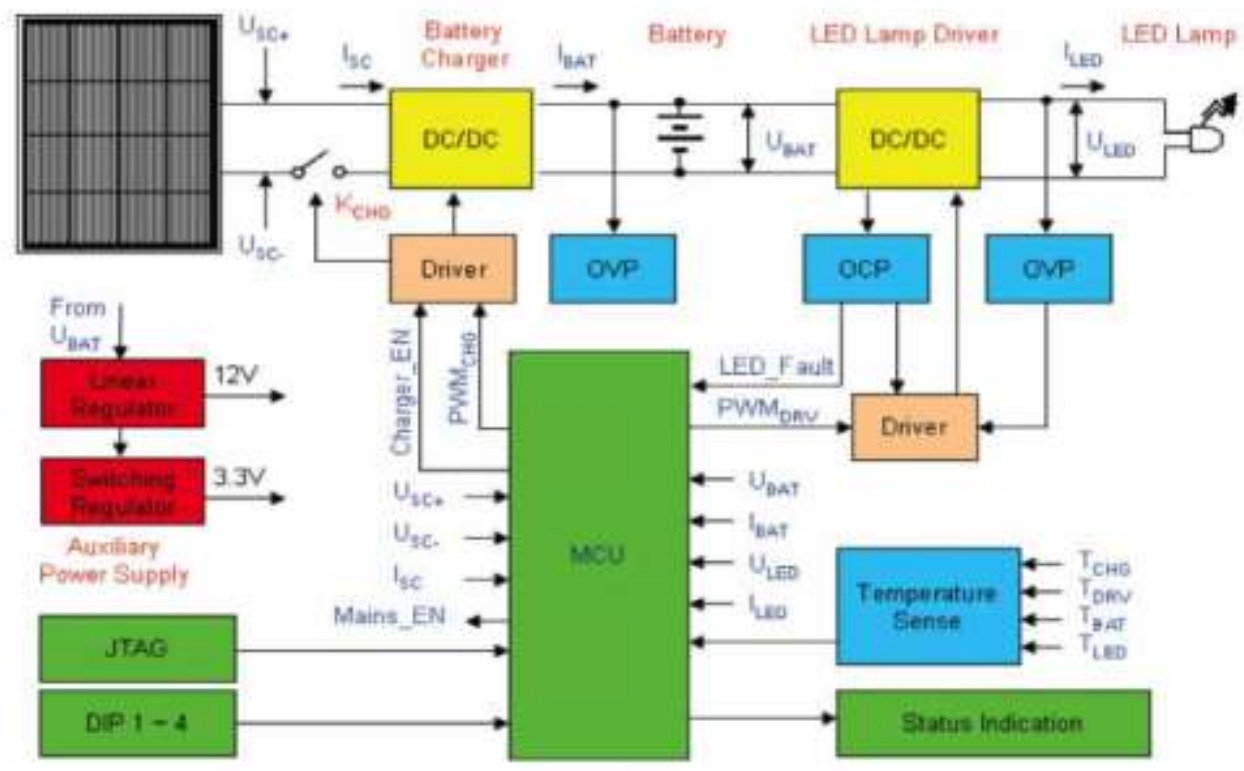

Figure 1. Charge Controller System Configuration Block Diagram

The BMS of Li-ion battery that check and manage the status of Li-ion battery pack at $12 \mathrm{~V}, 24 \mathrm{~V}$ and $48 \mathrm{~V}$ of operating voltage for MPPT-applied Li-ion battery charge controller used in the solar LED lighting system mainly consists of the sensing part, control part and communication part.

The sensing part detects voltage, current and temperature per stack consisting of each cell in the Li-ion battery pack, while the control part detects charge/discharge status based on the real-time data of Li-ion battery stack received from the sensing part and send the control signal to the sensing part according to the BMS algorithm. The communication part combines and sends the real-time status information detected by the sensing part and the battery status information detected by the control part to the MPPT-applied charge controller and the integrated monitoring system via wireless communication. In addition, the switch to prevent unbalanced charge and the protective circuit to prevent risk of explosion by high temperature are added on each stack.

\subsection{Plumbic Acid/Lithium-Ion Battery Pack Design}

The plumbic acid/lithium-ion battery pack is designed to include switching function to control low voltage level of cells to be balanced with the other cells, so not to be affected by surrounding environments including temperature and humidity, as described in Figure 2 .

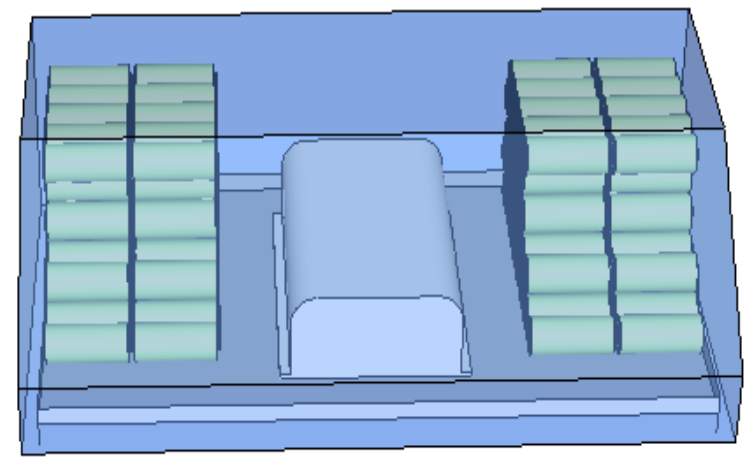

Figure 2. Battery Pack Mechanism Design 


\subsection{Wireless Sensor Network}

The wireless sensor network output the information in the monitoring system via the wireless communication module at $447 \mathrm{MHz}$ of radio frequency, which makes free monitoring via conversion from the RF (Radio Frequency) communication data to the $\mathrm{TCP} / \mathrm{IP}$ communication data by the converter, as described in Figure 3.

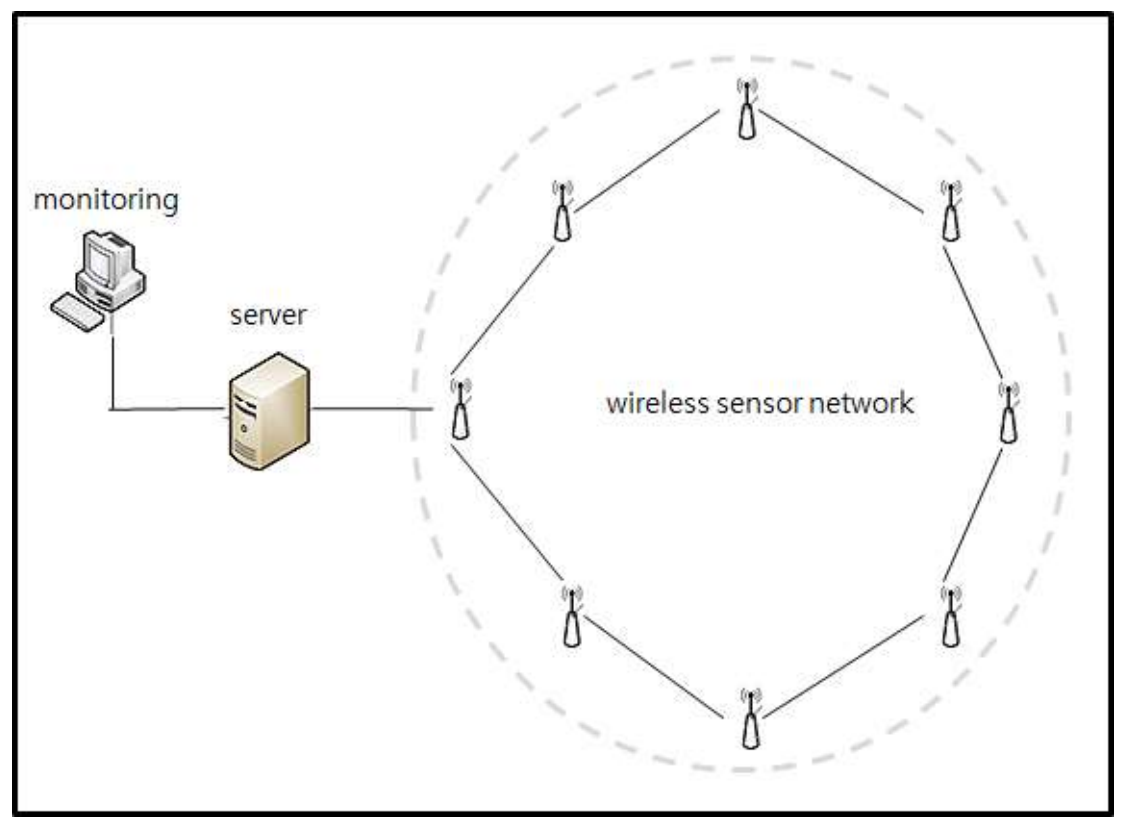

Figure 3. Wireless Sensor Network Conceptual Diagram

\subsection{Integral Management and Remote Control System}

The integral management and remote control system is designed to save the solar LED lighting status information in the established database and remotely control such information via the PC-based software for lighting time setting and remote control/maintenance, as described in Figure 4.

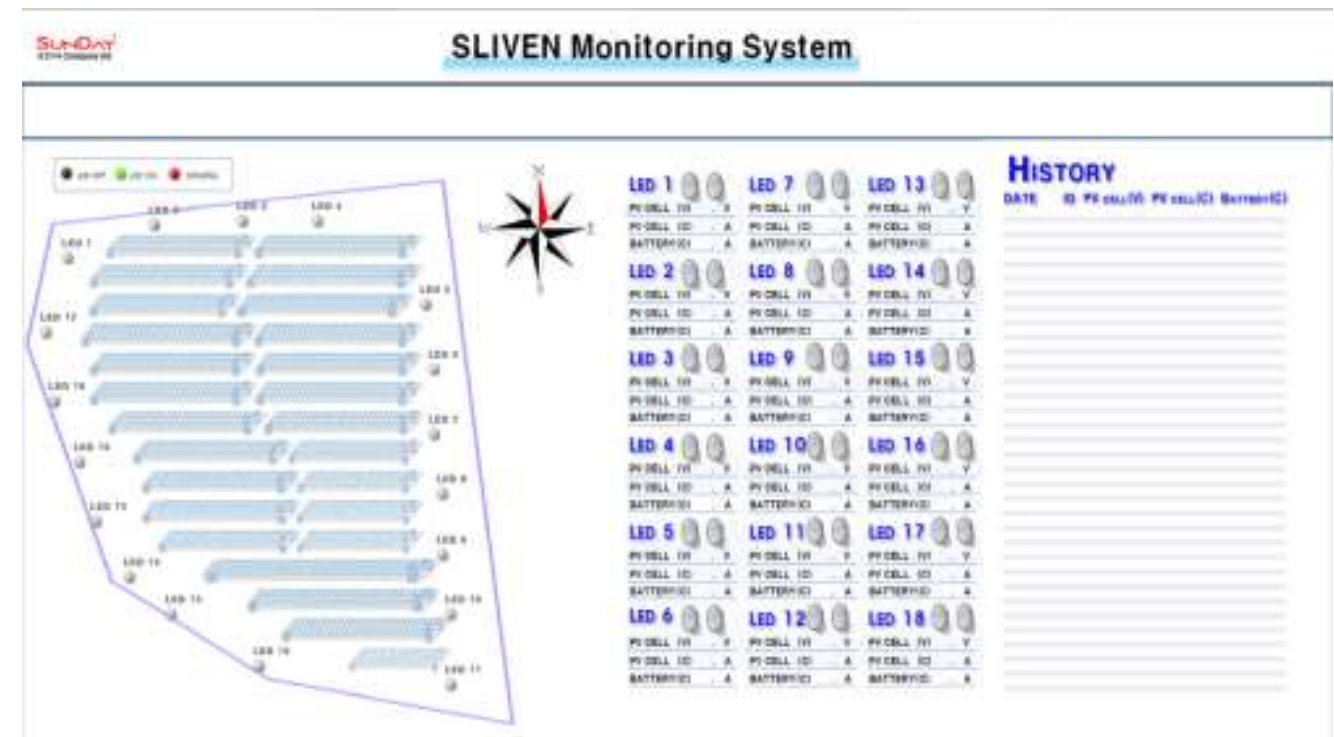

Figure 4. Integral Management and Remote Control System 


\section{Additional Component Technology}

\subsection{Moving Object Recognition-Lighting Control System Applying Signal Processing-Based Sound Recognition Technology}

The complex solar LED lighting security system combines 5 common technological components mentioned above, the moving object recognition-lighting control system applying signal processing-based sound technology and the inter-solar module mismatch control technology. The moving object recognition-lighting control system applying signal processing-based sound recognition technology recognizes sound from the moving object such as a vehicle or person via the signal processing-based sound recognition technology and reduces lighting energy consumption by controlling the light according to the recognized information. It detects sound that is produced a moving vehicle from the complex sound information collected by two microphone sensors such as noise produced by rain, wind and vehicle and voice produced by a person and extracts direction of moving vehicle based on time interval between two sensors. Based on this basic technology, the intruder detection system was developed to detect the sound from moving person by increasing sensitivity of microphone sensor and utilizing sophisticated filtering technology.

\subsection{Intruder Detection System}

As described in Figure 5, the intruder detection system established an invisible ray barrier to detect intruders collects video information from the security camera and lights the surrounding.

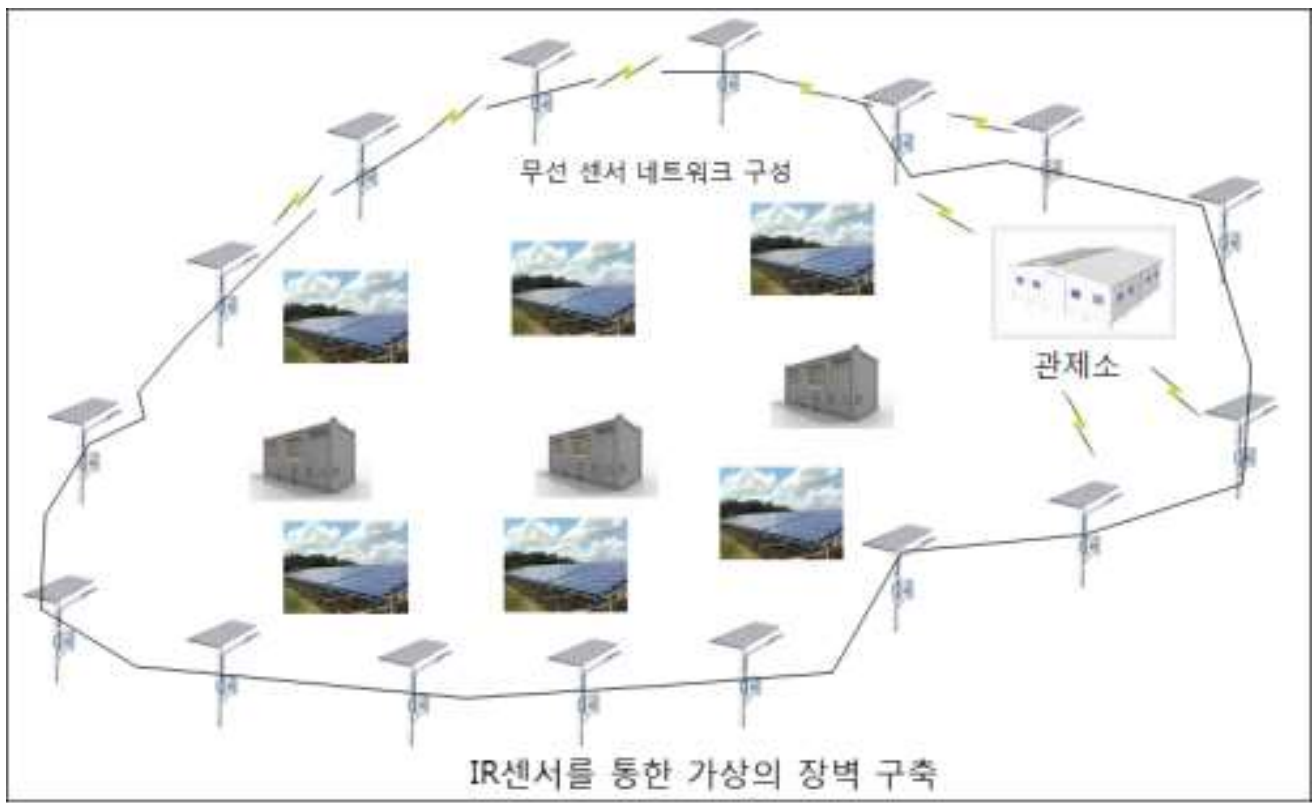

Figure 5. Large-Scale Facilities and Equipment Security Systems

\subsection{Network Video and Intrusion Information Monitoring System}

The network video and intrusion information monitoring system displays intruder location information detected by the intruder detection system as well as video information collected by the security camera and sound an alarm to report intrusion to the manager, as described in Figure 6. 


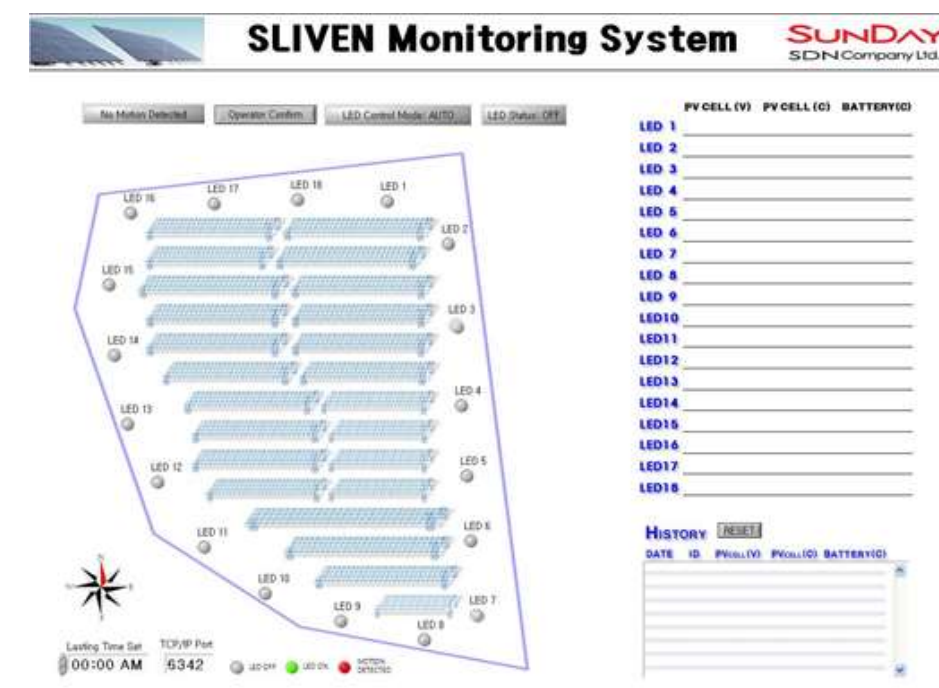

Figure 6. Network Video and Intrusion Information Monitoring System

As described in Figure 7, the intuitive GUI was designed and developed for real-time monitoring and the wireless sensor network was used for remote and automatic control of light. In addition, the inter-module mismatch monitoring and security system and the DB to save and maintain lighting status information were established and the reliability and validation test was conducted via the experiments in the IMW solar power generation demonstration complex.

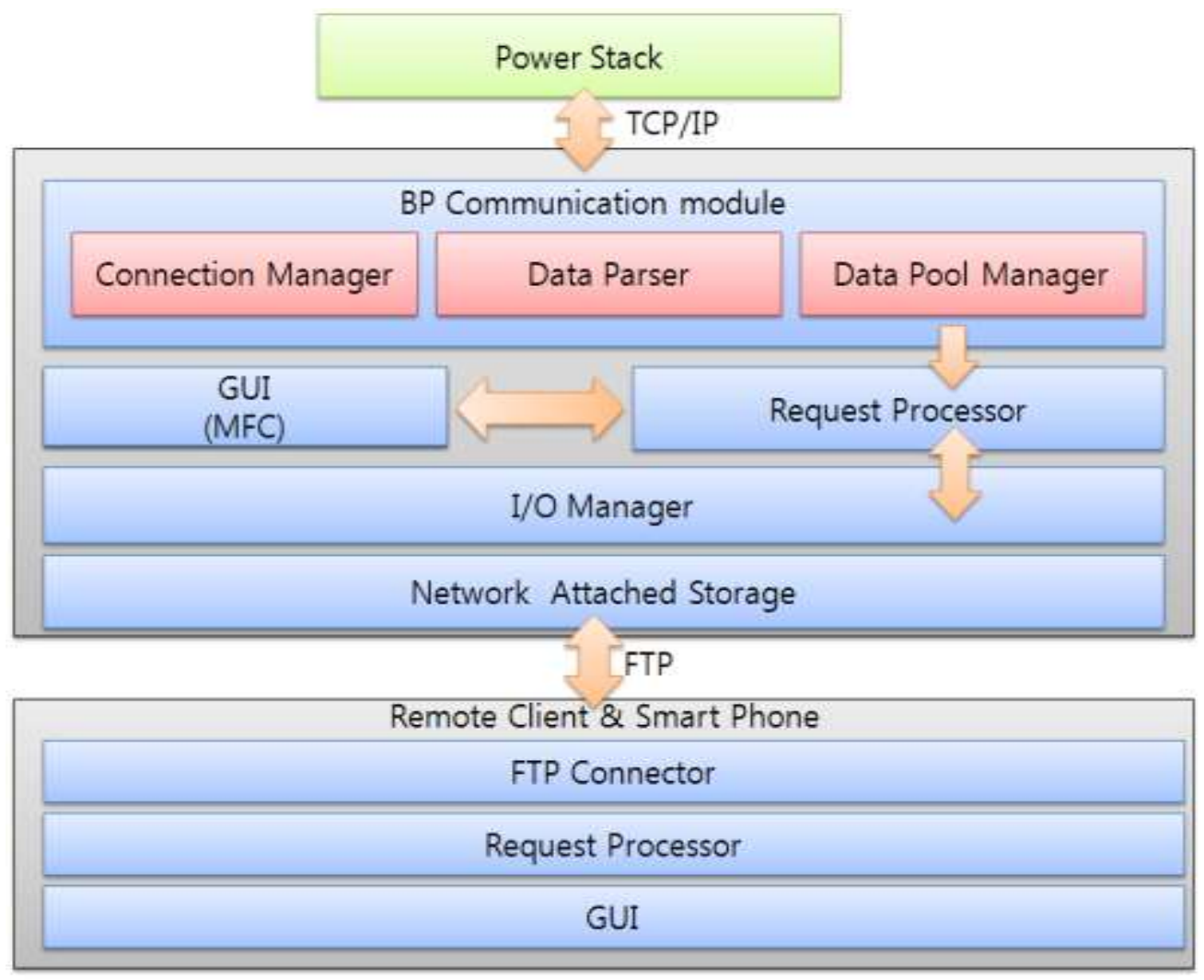

Figure 7. GUI Block Diagram for Real-Time Monitoring 


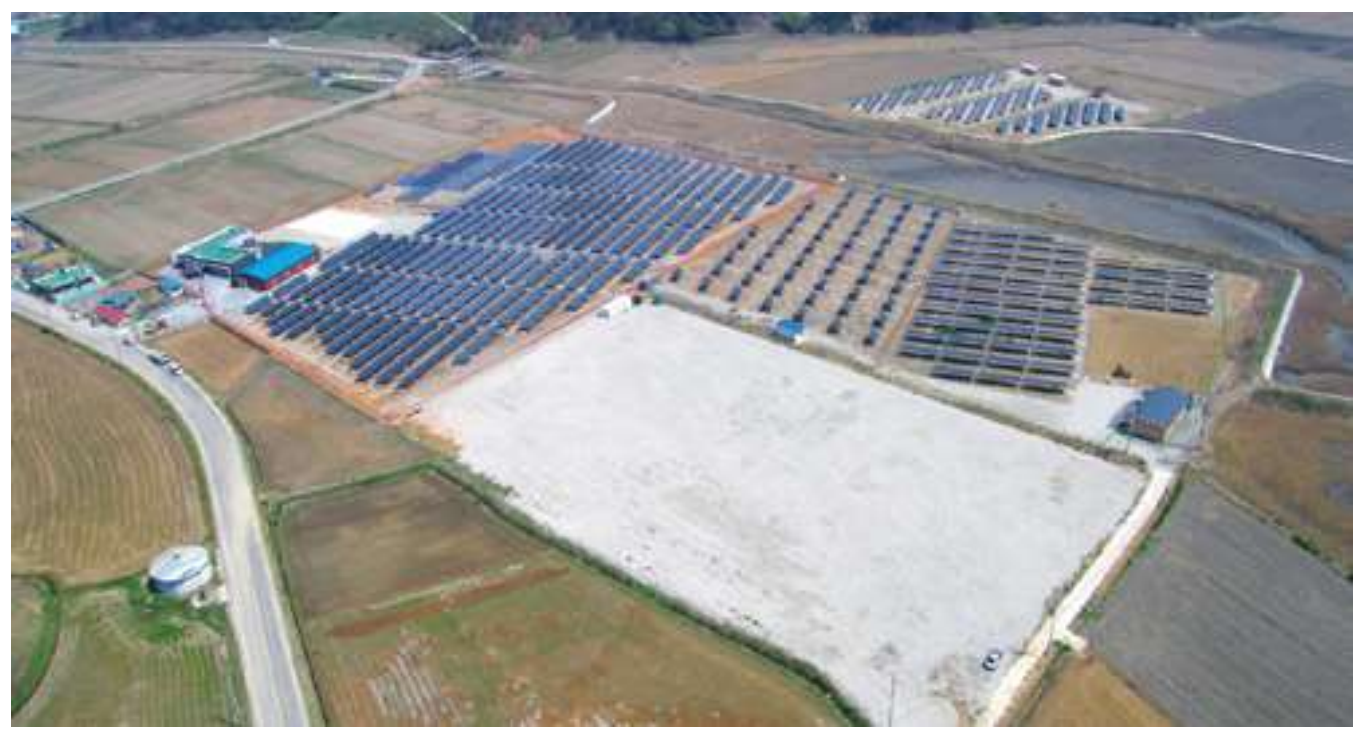

Figure 8. 1MW Solar Power Generation Demonstration Complex

\subsection{Complex Solar LED Lighting Security System Applying Signal Processing-} Based Sound Recognition Technology

Development of complex solar LED lighting security system applying signal processing-based sound recognition technology was completed by combining entire relevant technologies such as CTV, search light, IR sensor and intrusion monitoring system using sound recognition.

The solar light charge controller was designed to apply the hybrid system for conversion to power supply for common use depending on battery/PV cell status information as described in Figure 10 and lead to maximum efficacy of PV cells by including MPPT function [10-12].

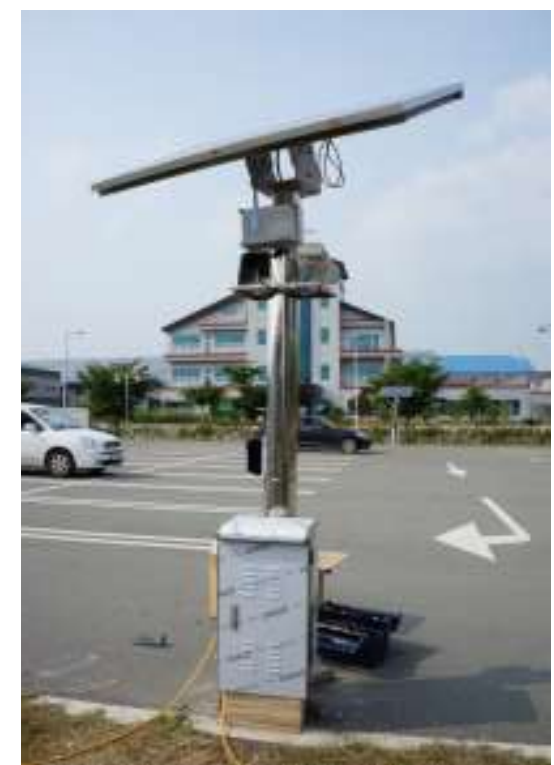

Figure 9. Complex Solar LED Lighting Security System Applying Signal Processing-Based Sound Recognition Technology 


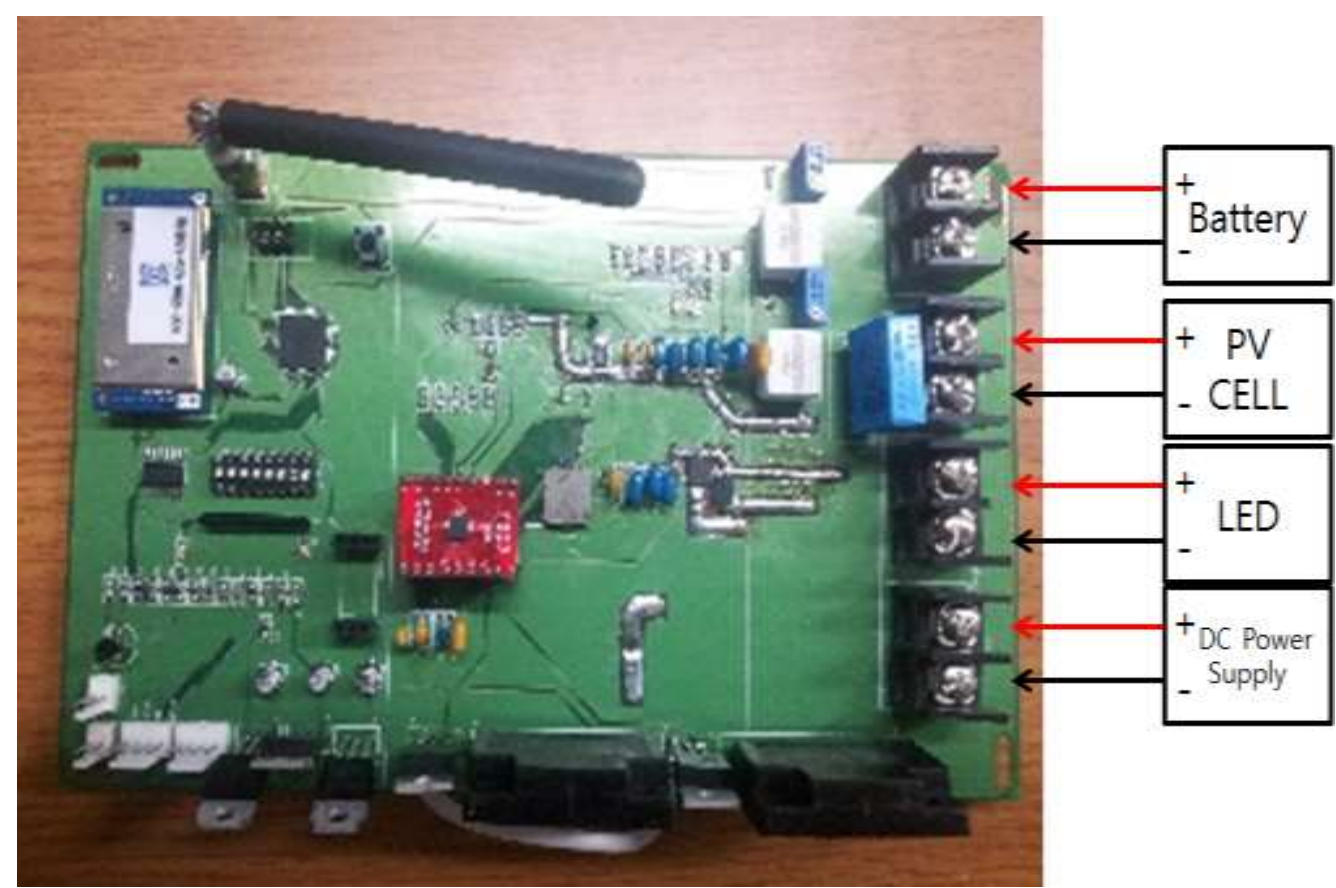

Figure 10. Solar Charge Controller and Hybrid System

In addition, it is configured by an algorithm to block the battery voltage after approving the DC power supply to prevent power supply cutoff if the battery voltage declines to $23.2 \mathrm{~V}$ while not being charged; the relevant experiment results are provided in graph in Figure 11.

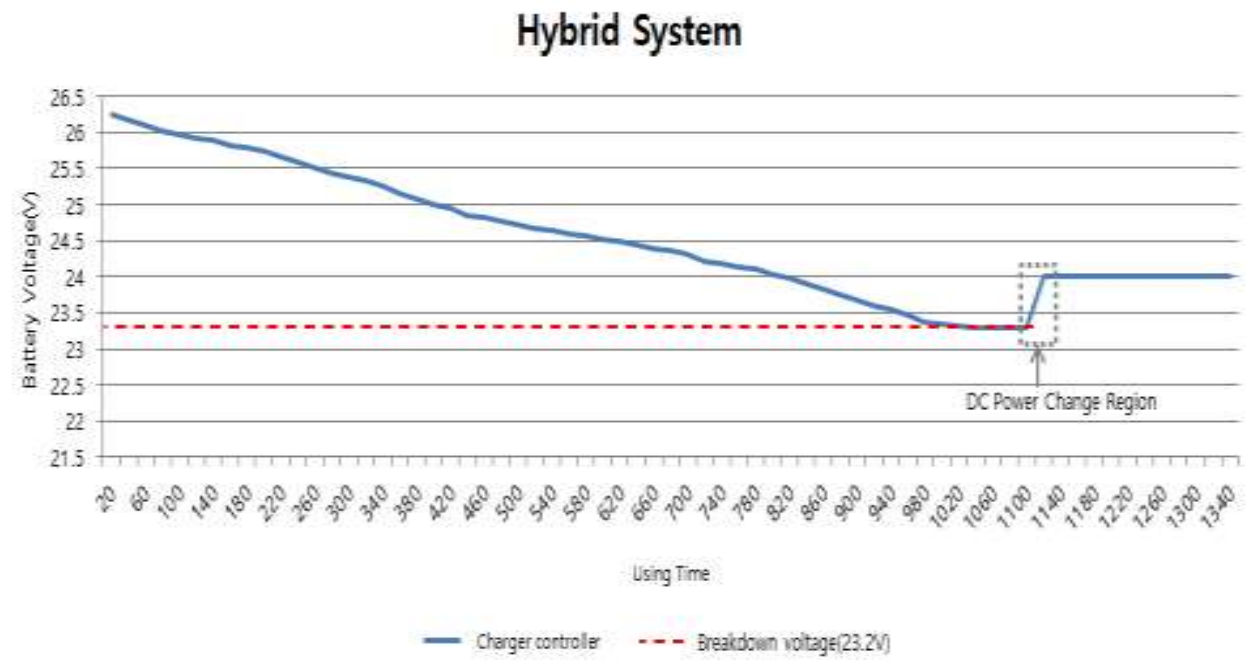

Figure 11. Hybrid System Experiment Results

\section{Conclusion}

The complex solar LED lighting security system applying signal processing-based sound recognition technology provides the independent solar LED light with intelligence to determine intrusion and control the light and nerve network to make inter-sensor communication between lights, to intelligently control the lights and at the same time to provide integral solution for automatic, remote monitoring and control by displaying the location of intrusion on the $\mathrm{PC}$ at the remote control center when intrusion occurs. 
As described in Figure 12, independent solar LEDs are placed in the solar lighting site at constant interval. Each solar light operates the security system using the voltage of PV cells and charges the battery in maximum efficacy via MPPT function in day time, while continuing to be turned on by specific time point by using the pre-charged battery power and thereafter turned off until intrusion is detected. The protective wall is created between solar LET lights by using the IT sensor. If intrusion entering into the sensor wall occurs, the light is turned on and intrusion information is sent to the control center in real time. In situation that the battery cannot supply sufficient power to the LED lights and the security system due to continual lack of sunshine, safety is guaranteed by conversion to power supply for common use. In addition, battery monitoring not only minimizes OPEX required for maintenance of battery but also guarantees reliability to maintain the security system even in harsh environment (uncharged situation due to lack of long-term sunshine). Additionally, the IP camera with costly infrared-ray function is not need as the LED lights are turned on when intrusion occurs.

Approximately 20 solar lights are installed if PV cells for solar lights apply to the solar power plant in $2 \mathrm{~km}$ of circumference, which involves in 3.5 hours of mean sunshine and annual KRW > 4,000,000 expenses with KRW 700 generation cost. Using such amount of PV cells as a part of energy plant might be unreasonable. Using electricity for common use does not meet the purpose of new renewable energy distribution. Therefore, the environment-friendly green lights using new renewable energy at the point to reach the grid parity are considered to be reasonable and long-term oriented in every aspect including technology, cost, environment, etc. and to be able to preoccupy the light market in the future.

This technology is applicable to not only solar plants but also other facilities and able to enter the next generation, independent solar LED streetlight market as it is directly convertible to the environment-friendly and high efficiency streetlight system for e.g., less than four-lane local roads and bike lanes.

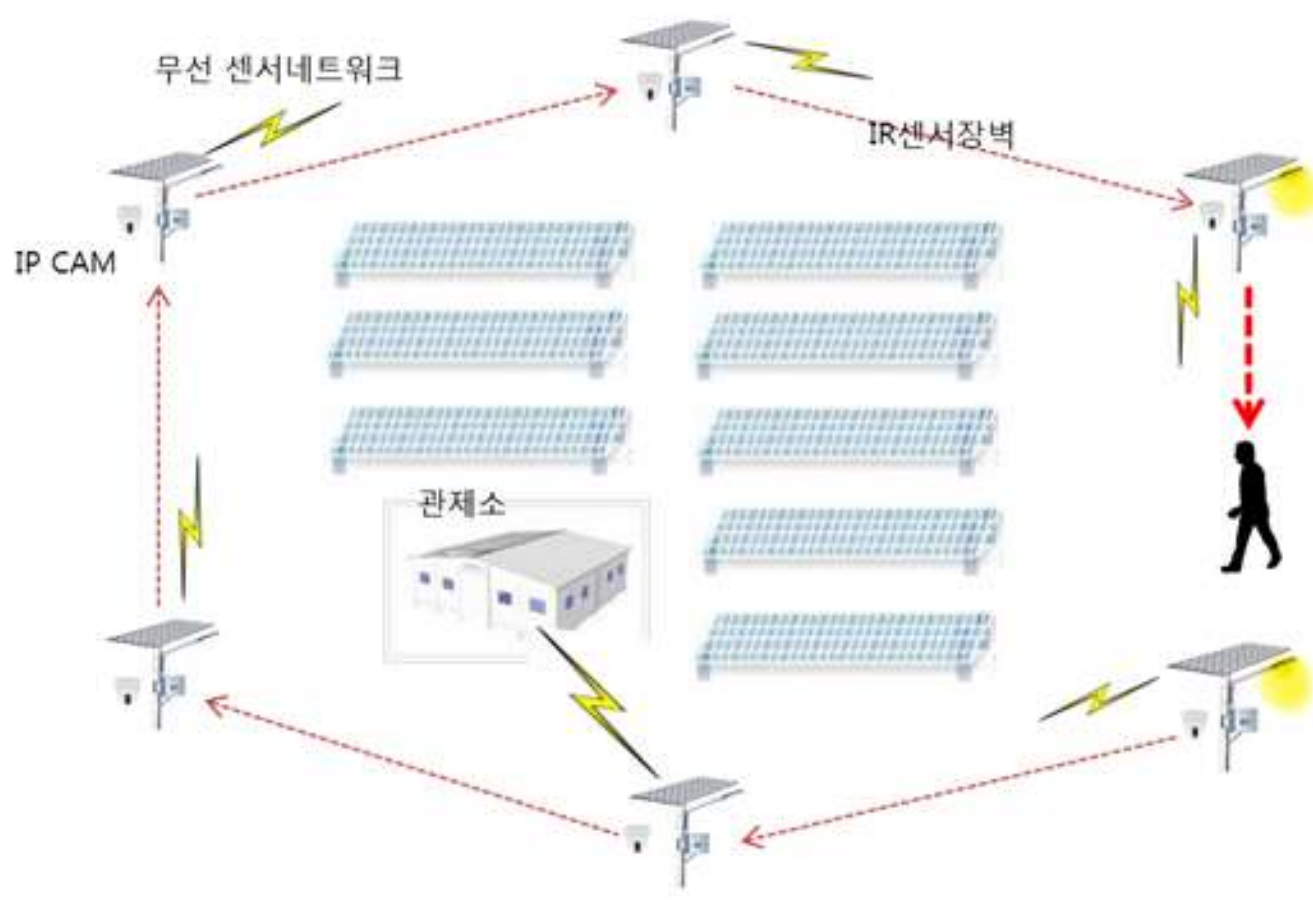

Figure 11. Example of Application of Complex Solar LED Lighting Security System Applying Signal Processing-Based Sound Recognition Technology 


\section{Acknowledgments}

This work was supported by the 2016 Research Fund of University of Hanseo.

\section{References}

[1] S. I. Hong and C. H. Lin, "The Hybrid Lighting Control System on Multiple Sensor", Journal of IKEEE. IKEEE, vol. 17, no. 3, (2013) September, pp. 301-308.

[2] A. Mehta, A. Vyas, N. Bodar and D. Lathiya, "Design of Solar Distillation System", International Journal of Advanced Science and Technology, vol. 29, (2011) April, pp. 67-74.

[3] M. Hajian, "Various Aspects of Solar Energy Utilization: Review", International Journal of Advanced Science and Technology, vol. 58, (2013) September, pp. 41-50.

[4] S. Das and A. Kumar, "Concept of an Electromagnetic Solar Based Power Drive for Automobile", International Journal of Advanced Science and Technology, vol. 76, (2015) March, pp. 21-26.

[5] M. K. Iqbal, T. Islam, M. Chowdhury and A. Imteaj, "Construction of Single Axis Automatic Solar Tracking System", International Journal of u - and e - Service, Science and Technology, vol. 8, no. 1, (2015) January, pp. 389-400.

[6] G. Zhang, X. Wang and Z. Du, "Research on the Prediction of Solar Energy Generation based on Measured Environmental Data", International Journal of u - and e - Service, Science and Technology, vol. 8, no. 5, (2015) May, pp. 385-402.

[7] R. Angamuthu and B. Govindan, "Integration of Standalone Solar Power System with Flying Capacitor Multilevel Inverter Contingent on Synchronous Sequential Circuit", International Journal of u - and e Service, Science and Technology, vol. 9, no. 11, (2016) November, pp. 105-120.

[8] S. H. Cho, Y. S. Song and D. W. Lee, "Lighting Control Management System for Efficient Energy Saving", Proceedings of KIIT Summer Conference, (2010) May, pp. 276-279.

[9] D. S. Hyun, M. H. Jang, N. I. Jeong, D. G. Kim, Y. O. Choi and G. B. Cho, "Photovoltaic Streetlight System using Ni-MH Battery", Proceedings of KIPE Conference, (2008) June, pp. 618-620.

[10] H. J. Kang, S. M. Kim, T. W. Moon, H. B. Kwak and J. H. Ryu, "A Study on the Hybrid LED Controller for Road Lamp", Proceedings of KICS Conference, (2010) February, pp. 622-623.

[11] Y. S. Lee, N. I. Kim, S. W. Jeong and J. H. Gim, "The Development of Stand-alone LED Streetlight Controller using Wind/Photovoltaic Hybrid system", Proceedings of KIEE Conference, (2012) July, pp. 892-893.

[12] S. Nunoo, J. C. Attachie and C. K. Abraham, "Using solar power as an alternative source of electrical energy for street lighting in Ghana. Innovative Technologies for an Efficient and Reliable Electricity Supply”, Proceedings of CITRES Conference, (2010) October, pp. 467-471.

\section{Authors}

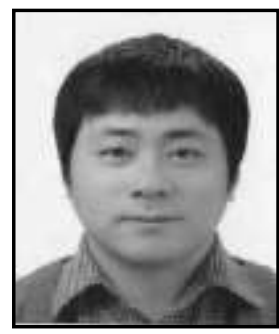

Wonchul Choi, he received his B.S. degrees in Electronic engineering at Hanseo University, Seosan, Korea in 2011, and M.S. degrees in Electronic Engineering at Hanseo University, Seosan, Korea in 2014, His current research interests include the embedded system and micro controller unit.

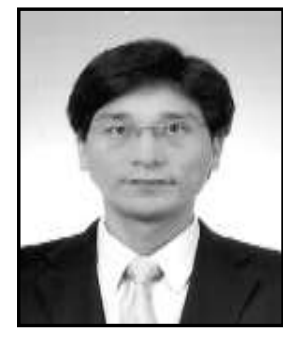

Choongchae Woo, received the B.S. degrees in Electronic engineering at Sunchon National University, Sunchon, Korea in 2000, and M.S. and Ph.D. degrees in Electrical and Electronic Engineering at Yonsei University, Seoul, Korea in 2002, and 2007, respectively. From September 2007 to February 2009, he was a senior engineer in Samsung Electronics, Suwon, Korea where he developed Mobile WiMAX systems for broadband wireless services. In March 2009, he joined the Department of Electronics Engineering at the Hanseo University as an Assistant Professor. His current research interests include the field of wireless communications focusing on multicarrier systems and resource allocation algorithms. 